architecture' or text format, as well as two different word processor programs that could understand the format. But the universities never reached the point at which their software could share files, and the project was killed last year.

The only concrete product to come from the NSF project was a simple text processor called PS-Express, which is now widely distributed among scientists. It converts a simple list of data elements (such as 'Last Name $=$ Mathis') into a file written in the common Postscript graphics language. When sent to a Postscript-compatible printer, the file prints out an entire NSF application form with all data filled in.

NSF also accepts PS-Express files electronically, over the Internet computer network. Some 200 applications have been filed that way in the past two years.

But electronic submission at NSF "is still a very hand-held process," says Lawrence Edwards, NSF senior project manager for office information systems. "When we get an application electronically, I print it out, take it downstairs and put it in the queue, just like it came in the mail."

NSF is now developing a simple 'extract' program that will read the PS-Express files and automatically transfer $20-30$ essential data elements into the main NSF database, without the need to type it in. That saves time, and more importantly, errors.

But more ambitious projects are in abeyance until the NIH experiments prove that researchers, administrators, agency officials and the technology are all ready for the leap.

So far, government acceptance of the electronic grant projects has been cautious - for good reason. Although the technology has come far in the past ten years, most computer monitors are still barely adequate to display an entire application page at once, clearly or not. "I'd hate to read a proposal on the screen," Edwards says.

And at NIH, Mathis is still fighting computer phobia. "We're waiting for a generational change," he says. "People keep telling me, "John, what you're doing is terrific. I just hope I retire first."

Mathis takes the long view. "Everybody knows that (electronic grants) are inevitable," he says, "it's just a question of when to buy in. If you want to be on the cutting edge and to have a lot of fun, you do it now. Otherwise, you step back and let everybody work the bugs out."

Bugs or not, cultural resistance remains the largest hurdle to electronic grants. Mathis and his staff spend much of their time visiting universities, other parts of NIH and federal agencies to preach the gospel of computerized applications. These "dog and pony shows", as Mathis describes them, are intended to create a groundswell of demand. Until Mathis and Edwards can convince university administrators that electronic grants save time and trouble, the weak link in the chain will continue to be the human one.

Christopher Anderson

\section{Munich}

As anyone who has tried in recent months to place a call from western Germany to eastern Germany can attest, the two telephone systems are anything but unified. A re-dial button or a rubber finger is a virtual necessity, since the few available lines are always busy.

But now the national telephone company Telekom is bringing in high technology to widen the bottleneck in at least a few geographic areas until a more thorough upgrading of eastern Germany's antiquated system can be carried out. Earlier this month, Telekom began switching calls between some eastern and western cities by satellite in an efficient, if expensive, attempt to alleviate the situation.

From 5 April, Telekom made available 30 additional satellite lines between the western city of Hamburg and the eastern city of Dresden to complement the paltry 24 land lines previously available.

Hamburg has a population of more than 1.6 million; Dresden has 500,000 residents and is the third-largest city in eastern Germany. An additional 36 lines are expected to be added later this month.
It is the first time a satellite has been used to route public calls between the two parts of Germany. The satellite, known as Kopernikus, is normally used for intercontinental calls.

But the stopgap use of the satellite does little to ease the misery of private and corporate customers in other regions of Germany. Telekom, and the Ministry of Post and Telecommunications to which it belongs, have been lambasted in the German press for their sluggish response to the immediate need for more telephone lines between the two regions of Germany. As Telekom has a monopoly on offering basic telephone service, there is nowhere else the customers can turn.

Telekom is planning to invest DM55,000 million (about $\$ 33,000$ ) by 1997 to rebuild the neglected eastern German telephone infrastructure. A temporary network, known as an overlay network, is expected to be in place by July. It will be used as an adjunct to the existing network in eastern Germany, most of which was installed back in the 1920s.

Steven Dickman

\title{
Gaussian curve graces banknote
}

\section{Göttingen}

THE German mathematician and astronomer Carl Friedrich Gauss (1777-1855) is honoured on a new German 10-mark banknote issued on 16 April in Göttingen. The bill marks the second time in as many years that a German banknote has been issued featuring a scientific luminary. Last year, immunologist Paul Ehrlich was so honoured (see Nature 347,$415 ; 1990$ ).

Gauss, for whom approximately $\mathbf{5 0}$ mathematical laws, formulae and methods have been named, was head of the Göttingen astronomical observatory from 1807 to 1855 . One of the founders of modern geophysics, Gauss became famous during his lifetime for his method of measuring magnetic fields in absolute units, which later became known as gaussian units, including the gauss (for magnetic field strength).

In addition to a portrait of Gauss, the face of the note features the familiar gaussian distribution. The reverse side features a 'viceheliotrope', a type of sextant used for surveying invented by Gauss to divert a ray of sunlight to a distant observer. Circles in the background represent stylized plane-
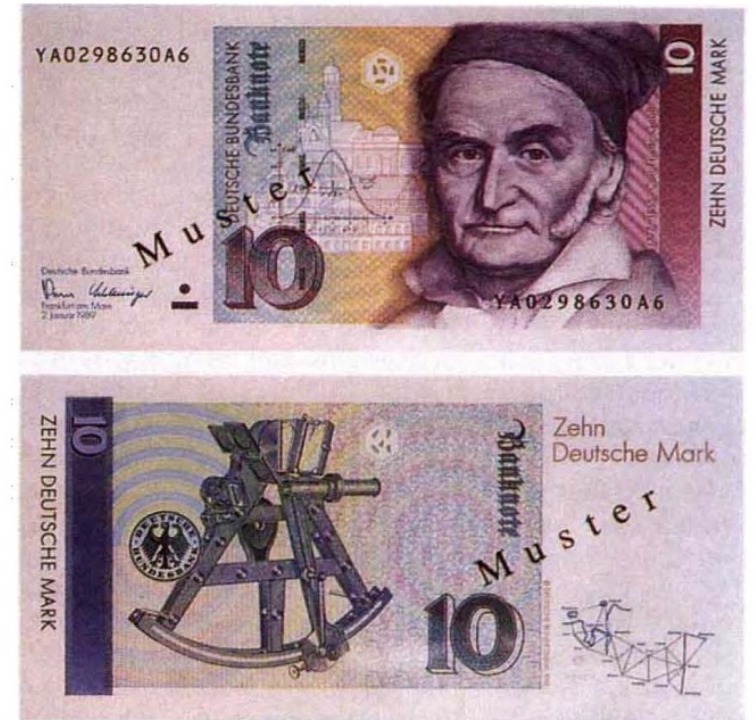

Gauss is latest in the line of scientists to receive recognition on German currency.

Gauss is latest in the line of scientists to receive recognition on German currency.

In 1992, a third figure from German scientific history, this time a woman, will appear on a new 500-mark note: Maria Sibylla Merian (1647-1717), who compiled a famous catalogue of drawings of insects. The series of notes is designed to depict great personalities of German cultural life. StevenDickman 